\title{
How do yeast sense mitochondrial dysfunction?
}

\author{
Dmitry A. Knorre ${ }^{1}$, Svyatoslav S. Sokolov ${ }^{1}$, Anna N. Zyrina ${ }^{2}$, Fedor F. Severin ${ }^{1,3, *}$ \\ ${ }^{1}$ Belozersky Institute of Physico-Chemical Biology, Moscow State University, Leninskiye Gory 1-40, Moscow 119991, Russia. \\ ${ }^{2}$ Faculty of Bioengineering and Bioinformatics, Moscow State University, Leninskiye Gory 1-73, Moscow 119991, Russia. \\ ${ }^{3}$ Institute of Mitoengineering, Moscow State University, Leninskiye Gory 1, Moscow 119991, Russia. \\ * Corresponding Author: \\ Fedor F. Severin, E-mail: severin@belozersky.msu.ru
}

\begin{abstract}
Apart from energy transformation, mitochondria play important signaling roles. In yeast, mitochondrial signaling relies on several molecular cascades. However, it is not clear how a cell detects a particular mitochondrial malfunction. The problem is that there are many possible manifestations of mitochondrial dysfunction. For example, exposure to the specific antibiotics can either decrease (inhibitors of respiratory chain) or increase (inhibitors of ATP-synthase) mitochondrial transmembrane potential. Moreover, even in the absence of the dysfunctions, a cell needs feedback from mitochondria to coordinate mitochondrial biogenesis and/or removal by mitophagy during the division cycle. To cope with the complexity, only a limited set of compounds is monitored by yeast cells to estimate mitochondrial functionality. The known examples of such compounds are ATP, reactive oxygen species, intermediates of amino acids synthesis, short peptides, Fe-S clusters and heme, and also the precursor proteins which fail to be imported by mitochondria. On one hand, the levels of these molecules depend not only on mitochondria. On the other hand, these substances are recognized by the cytosolic sensors which transmit the signals to the nucleus leading to general, as opposed to mitochondriaspecific, transcriptional response. Therefore, we argue that both ways of mitochondria-to-nucleus communication in yeast are mostly (if not completely) unspecific, are mediated by the cytosolic signaling machinery and strongly depend on cellular metabolic state.
\end{abstract}

doi: 10.15698/mic2016.11.537 Received originally: 14.06.2016; in revised form: 27.08.2016, Accepted 30.08.2016, Published 22.09.2016.

Keywords: mitochondria, yeast, retrograde signaling, ROS.

\section{Abbreviations:}

AMPK - 5' adenosine monophosphateactivated protein kinase, MOTS- $c$ - mitochondrial open reading frame of the $12 S$ rRNA-c, mPOS - mitochondrial precursor overaccumulation stress,

ROS - reactive oxygen species, TOR - target of rapamycin.

\section{INTRODUCTION}

In present-day eukaryotes mitochondria play multiple roles such as oxidative phosphorylation, Fe-S clusters biosynthesis, thermogenesis and others (see for review [1-3]). Some special features of mitochondria make them a unique cellular signaling center. First, mitochondria have two compartments separated from the cytoplasm. Outer membrane is impermeable for molecules with molecular weight above $8 \mathrm{KDa}$ [4], thus the intermembrane space sequesters signaling macromolecules. Indeed, in higher eukaryotes the intermembrane space proteins serve as transducers of programmed cell death activation cascade [5]. The list of such proteins includes specific signaling molecules such as Smac [6] and Diablo [6], as well as proteins with well established "day-job" function, e.g. cytochrome $c$, which in higher organisms binds cytosolic Apaf- 1 complex to promote apoptosis [7]. In yeast, cytochrome $c$ was also suggested to have a pro-apoptotic function $[8,9]$, although its cytoplasmic target is still not found. The inner membrane is im- permeable for low molecular weight molecules, thus the matrix is able to entrap some metabolic intermediates and ions. Second, mitochondria harbor many enzymes with cofactors capable for reduction of molecular oxygen. This makes mitochondria a potentially powerful source of superoxide and hydrogen peroxide $[10,11]$. Finally, mitochondrial appear to be a natural element of signaling network capable of signal integration. Indeed, mitochondria can converge different inputs by decreasing or increasing the transmembrane potential (e.g. via activation of respiratory chain activity). As the transmembrane potential controls transport of various compounds across mitochondrial membranes (see [12] for review) and also regulates functional states of inner membrane translocators [13], mitochondria can be regarded as an element of signal convergence.

What kind of cellular responses are triggered by mitochondria? As the main mitochondrial function is transformation of energy, one can expect metabolic enzymes to be 
the central targets of the mitochondrial signaling. Indeed, it was recently shown that overexpression of mitochondrial superoxide dismutase in mammalian cancer cells inhibits AMPK and upregulates glycolytic enzymes via increased flux of hydrogen peroxide [14]. Moreover, there are a lot of metabolic enzymes among the targets of retrograde (mitochondria-to-nucleus) signaling cascade mediated by Rtg1/Rtg3 transcription factors (see for review [15]). Next, as mitochondria partially rely on their own DNA, mitochondrial DNA damage can cause mitochondrial dysfunction. Indeed, there are several stresses that are more damaging for mitochondrial than for nuclear DNA. An example of such stress is the exposure of yeast cells to anoxia ([16]; see also [17] for review). In such cases the feedback is required by the nucleus to change the levels of the nuclearencoded mitochondrial proteins accordingly. It is important to mention here that the nuclei encode most of the proteins localized in mitochondria. Furthermore, a set of changes in mitochondria are required during cell division. Although there are convincing data that in yeast cell cycle arrest does not inhibit replication of mtDNA $[18,19]$, the recent data suggests that mitochondrial biogenesis is thoroughly coordinated with the cell cycle stages [20].

In our review we argue that in yeast the major known routes of mitochondrial signaling are moderated by nonmitochondrial inputs. Despite the importance and complexity of mitochondrial activity, yeast cells, apparently, do not monitor mitochondrial functional state directly. Instead, they monitor important mitochondrially-produced substances, the levels of which also depend on nonmitochondrial factors. The cellular reactions to the imbalances in such substances are also not mitochondria-specific but include modulation of mitochondria-independent processes.

\section{ATP VERSUS TRANSMEMBRANE POTENTIAL IN RTG- DEPENDENT MITOCHONDRIAL RETROGRADE SIGNALING}

Retrograde signaling pathway was originally discovered as a mechanism initiated by mitochondrial dysfunction [21]. As a result of its activation, the Rtg3 protein is translocated to the nucleus and activates expression of a set of genes which helps to cope with the dysfunction. In particular, the changes in the expression provide reconfiguration of metabolism aimed to maintain synthesis of vital amino acids (reviewed in [15]). One of the possible reasons of mitochondrial dysfunction is exposure of yeasts to specific mitochondrial inhibitors (most of those are produced by bacteria or fungi $[22,23])$. Thus, one of the responses induced by Rtg1/Rtg3 transcription factors is the induction of pleiotropic $A B C$-transporters expression, that can prevent the delivery of unwanted xenobiotics to mitochondrial targets [24], although the precise mechanism of pleiotropic drug resistance activation is still unknown [15]. Rtg2 protein is proposed to be an initiator of this pathway (see reviews $[15,25])$, however, the existence of additional upstream signaling proteins cannot be excluded. Are there any specific Rtg2 ligands responsible for its activation? At least three possible parameters are usually considered as potential hallmarks of mitochondrial dysfunction: alterations in the levels of nucleotide triphosphates, mitochondrial transmembrane potential and reactive oxygen species (ROS, see [26]). It was previously shown that introduction of the ATP1-111 mutation in the cells lacking mitochondrial DNA ( $r h o 0)$ increases the mitochondrial transmembrane potential and at the same time prevents expression of the downstream events of the retrograde signaling (i.e. Rtg3GFP relocalization to the nuclei, [27]). This points at the role of the transmembrane potential, although does not address the mechanism of the "sensing". Conversely, the in vitro experiments revealed the role of nucleotide triphosphate binding in activation of Rtg2. It was found that ATP in high concentration induces dissociation of Rtg2 from its downstream target Mks1 [28].

On the one hand, these data complement each other. On the other hand, concentration of ATP in the cells does not strictly correlate with mitochondrial transmembrane potential. Under conditions of active glycolytic flux and repressed respiratory chain mitochondria do not contribute significantly to the cellular ATP level [29]. Therefore, under such conditions, loss of mitochondrial DNA - the standard way to activate retrograde signaling response will not necessarily lead to a decrease in cytoplasmic ATP level. Thus, the effect of RhoO mutation could be dampened in high glucose concentrations. In agreement with this, it was shown that the level of background retrograde cascade activation is much higher in the cells grown on poor-fermentable carbon sources [30]. Moreover, in our hands [31], as well as in the previous high-throughput screen, rhoO mutation did not lead to an increase of mRNA of Rtg-targets [32]. Finally, the ATP-ase inhibitor oligomycin induces the set of genes that differs from the one activated by rhoO mutations or uncoupler CCCP [33]. This contradiction suggests that Rtg2 signaling depends on ATP level rather than on mitochondrial transmembrane potential.

To summarize, as ATP concentration does not depend on mitochondrial function only, Rtg pathway cannot be regarded as an exclusive mitochondria-to-nucleus signaling line.

\section{ABERRANT ACCUMULATION OF MITOCHONDRIAL} PRECURSORS IN THE CYTOSOL

Taken that Rtg2-mediated signaling is not specific to mitochondrial dysfunction, how do mitochondria provide feedback to the nucleus in case of mitochondrial problems? Higher eukaryotes harbor mechanisms for identification of dysfunctional mitochondria, which is based on impaired protein import [34-36]. Damaged mitochondria can induce compensatory response [36] or be removed by mitophagy, a mitochondria-specific branch of autophagy [35]. In both cases, the mitochondrial dysfunction retards import of specific proteins. In C. elegance, transcription factor ATFS-1 has double localization targeting. Inhibition of mitochondrial import induces its relocalization to the nucleus and activation of compensatory response [36]. In mammals, a decrease of the transmembrane potential activates mi- 
tophagy which relies on PINK and Parkin proteins (see for review [35]). S. cerevisiae lacks homologs of ATFS-1 or PINK/PARKIN systems. Are yeast cells able to get rid of mitochondria with low transmembrane potential? Although there are several works suggesting the role of mitophagy in yeast mitochondrial quality control [37-39], a specific mitochondrial autophagy in yeast is normally induced by starvation $[40,41]$. The latter fact points at the role of mitophagy in maintaining energy and nitrogen balances. Nevertheless, retention of the damaged mitochondria in the mother cell during cell division could ensure their clearance from the growing colony $[42,43]$. We suggested earlier that the presence of such a mechanism could substitute for selective mitochondrial mitophagy [44].

In any case, yeast cells do possess a specialized signaling pathway activated by a drop in the transmembrane potential. Recently it was reported that in yeast, a failure to import mitochondrially-targeted proteins activates mitochondrial precursor over-accumulation stress (mPOS) response, which suppresses the proteotoxic consequences of the precursor accumulation [45]. The set of proteins induced acts mainly to reduce the rate of protein biosynthesis. Interestingly, this type of unfolded protein stress, unlike the one caused by the heat shock (reviewed in [46]), does not induce accumulation of cytosolic chaperones which act to repair the misfolded proteins. The authors speculate that additional chaperones would not improve the situation: refolding of the cytosolically accumulated precursor proteins could even worsen the situation. Still, the question remains: do mitochondrial precursor proteins bind to a specific signaling ligand in the cytosol or, alternatively, accumulation of non-specific misfolded proteins in the cytosol can trigger mPOS network. The answer to this is not straightforward because conventional stresses causing protein misfolding are not specific to the cytoplasm: heat stress, mutations in the proteasomal genes or major molecular chaperones also cause an increase in proteins folded in the ER (reviewed in [47]). At the same time, there were many studies on ectopic expression of hard-to-fold human proteins in yeast: alpha-synuclein, polyglutaminerich fragments of huntingtin, etc. (see $[48,49]$ for review). Apparently, such expression differs significantly from a general proteostatic stress. Thus, to our knowledge, there are no data on the changes in the proteome caused by exclusively cytosolic bulk protein misfolding.

\section{AMINO ACIDS-BASED SIGNALING}

As a specific mitochondria-to-nucleus signaling based neither on inhibited protein import into mitochondrial matrix nor on mitochondrial transmembrane potential has not been shown so far, a question arises: how yeast cells can measure mitochondrial 'health'? Possibly, the simplest way to monitor mitochondrial state is to measure metabolic intermediates that are produced or modified specifically in mitochondria (see for review [50]).

Due to the fact that amino acid (i.e. glutamate and arginine $[51,52])$ biosynthetic pathways are localized in mitochondrial matrix, the cytoplasmic amino acids levels are good candidates for mitochondrial productivity indicators. Indeed, the deficit of glutamine activates Rtg pathway, leading to an increase in transcription of the mitochondrial enzyme Gln1p responsible for its synthesis [53]. Interestingly, similar to activation of Rtg by a decrease in ATP concentration, the final step of this pathway's activation by the drop in the amino acid concentrations also happens in mitochondria-independent fashion. While the molecular mechanism is rather complex $[54,55]$, it was convincingly shown that TOR (target of rapamycin) complex located in the cytosol senses the amino acid deficit and then directly activates Rtg2 protein [56, 57].

\section{RETROGRADE SIGNALING AND REACTIVE OXYGEN SPECIES}

Mitochondria are usually considered as a source of reactive oxygen species (ROS). The most common ROS are $\mathrm{O}_{2} \bullet^{-}$, $\mathrm{H}_{2} \mathrm{O}_{2}, \bullet \mathrm{OH}, \mathrm{NO} \bullet$ and ${ }^{1} \mathrm{O}_{2}$. If the level of ROS exceeds the capacities of the defense mechanisms, the cell reaches the state which is often referred to as "oxidative stress". A precursor of most of the ROS, superoxide anion $\left(\mathrm{O}_{2} \bullet-\right)$, is produced via nonenzymatic reduction of molecular oxygen by electron transport chain components (reviewed in [58, 59]). Hydrogen peroxide $\left(\mathrm{H}_{2} \mathrm{O}_{2}\right)$ is produced by dismutation of $\mathrm{O}_{2} \bullet-$, and can be reduced fully into water or partially into highly reactive hydroxyl radical $(\bullet \mathrm{OH})$ [60]. Some of TCA enzymes also contribute to generation of reactive oxygen species [61]. At the same time, mitochondria harbor a robust antioxidant system: for instance, the activity of mitochondrial catalase is several orders of magnitude higher [62] than the maximal rate of hydrogen peroxide production by dysfunctional mitochondria [63]. As a result, under normal conditions mitochondria do not export ROS, instead, they can be considered as a sink for them (see [10] for review). However, under stress the capacity of antioxidant systems can be exhausted and the direction of ROS flux can be reverted. For instance, an increase in cytosolic $\left[\mathrm{Ca}^{2+}\right]$ transforms yeast mitochondria into a major source of ROS (see [9] and references within). Moreover, it was shown that Rtg1-Rtg3 signaling pathway plays a hormetic role by increasing mitochondrial ROS production and in this way upregulating antioxidant enzymes [64].

In the states of dysfunction, mitochondria activate signaling to increase the levels of antioxidant enzymes which do not rely on respiratory chain functioning. In particular, it was shown that inhibition of respiratory complex III with myxothyazol induces expression of not only mitochondrial/peroxisomal catalase Cta1 [65] but also of cytosolic catalase Ctt1 and of unspecific stress response genes controlled by Msn2/Msn4 transcription factors [65]. These data indicate that oxidative stress response induced by mitochondrial dysfunction is general rather than mitochondriaspecific. This is in agreement with the data on ethanolinduced oxidative stress: it was shown that high doses of ethanol activate Yap1 $[66,67]$, the key cytosolic hydrogen peroxide sensor [68]. 


\section{Fe-S CLUSTERS AND HEME}

Yeast mitochondria are indispensable for synthesis of such iron-containing compounds as Fe-S clusters and heme. Is the deficit of such compounds perceived by the cells as a manifestation of mitochondrial malfunction? The answer seems to be negative. The signaling pathways initiated under such conditions include the following steps.

First, insufficient levels of either Fe-S clusters or heme induce mitochondria-mediated oxidative stress (reviewed in [69]). It is known that Yap1 is the central transcription factor activated by hydrogen peroxide. Interestingly, among other targets Yap1 promotes expression of plasma membrane iron transporters FET3 and FET4, iron regulon gene FRA2 and ISU1, product of which plays a scaffolding role during the assembly of Fe-S clusters [70, 71] Hem15, a protein mediating heme biosynthesis, is also among Yap1 targets [70]. There is also a specialized transcription factor, Hap1, which is directly activated by heme [72]. Importantly, heme synthesis depends not only on functional mitochondria, but also on iron and oxygen availability. At the same time, Hap1 is also sensitive to oxidative stress [73] and is known to induce the expression of mitochondrial and cytosolic genes responsible for respiration and for controlling oxidative damage [74-76]. Moreover, there is another heme-sensitive transcription factor - protein complex HAP, Heme Activator Protein [77]. HAP is the master regulator of the mitochondrial biogenesis in the yeast $S$. cerevisiae [78]. It was shown that HAP complex activity is sensitive to ROS signaling and can be restored by an antioxidant as well as by the overexpression of superoxide dismutase Sod1p [79].

Thus, it appears that a general oxidative stress response includes a branch which signals to increase the production of the mitochondrially-synthesized ironcontaining molecules. Conversely, the cells upregulate their antioxidant defenses in response to a deficit in the mitochondrially-produced iron-containing substances.

\section{MITOCHONDRIAL-DERIVED PEPTIDES}

Export of Fe-S cluster precursors from mitochondrial matrix in yeasts is mediated by Atm1p, which belongs to the large family of membrane proteins, ABC-transporters [80]. Atm1p is partly functionally redundant with the second $A B C$-transporter localized in mitochondrial inner membrane, Mdl1 [81]. At the same time, many ABCtransporters are able to transport various substrates with significantly different physico-chemical properties (reviewed in [82]). Accordingly it was shown that Mdl1 mediates export of short (6-20 amino acid) peptides, which can be a product of proteolytic degradation of the mitochondrial matrix proteins by Lon protease [83]. These peptides (or some of them) are obviously perfect candidates for the role of specific messengers of mitochondria-to-nucleus signaling activated by mitochondrial matrix overload with unfolded proteins. It was shown that the deletion of MDL1 gene changes the expression of several nuclear encoded genes under conditions of mitochondria dysfunction induced by the deletion of an important mitochondrial protease YME1, while the phenotype of MDL1 deletion in the

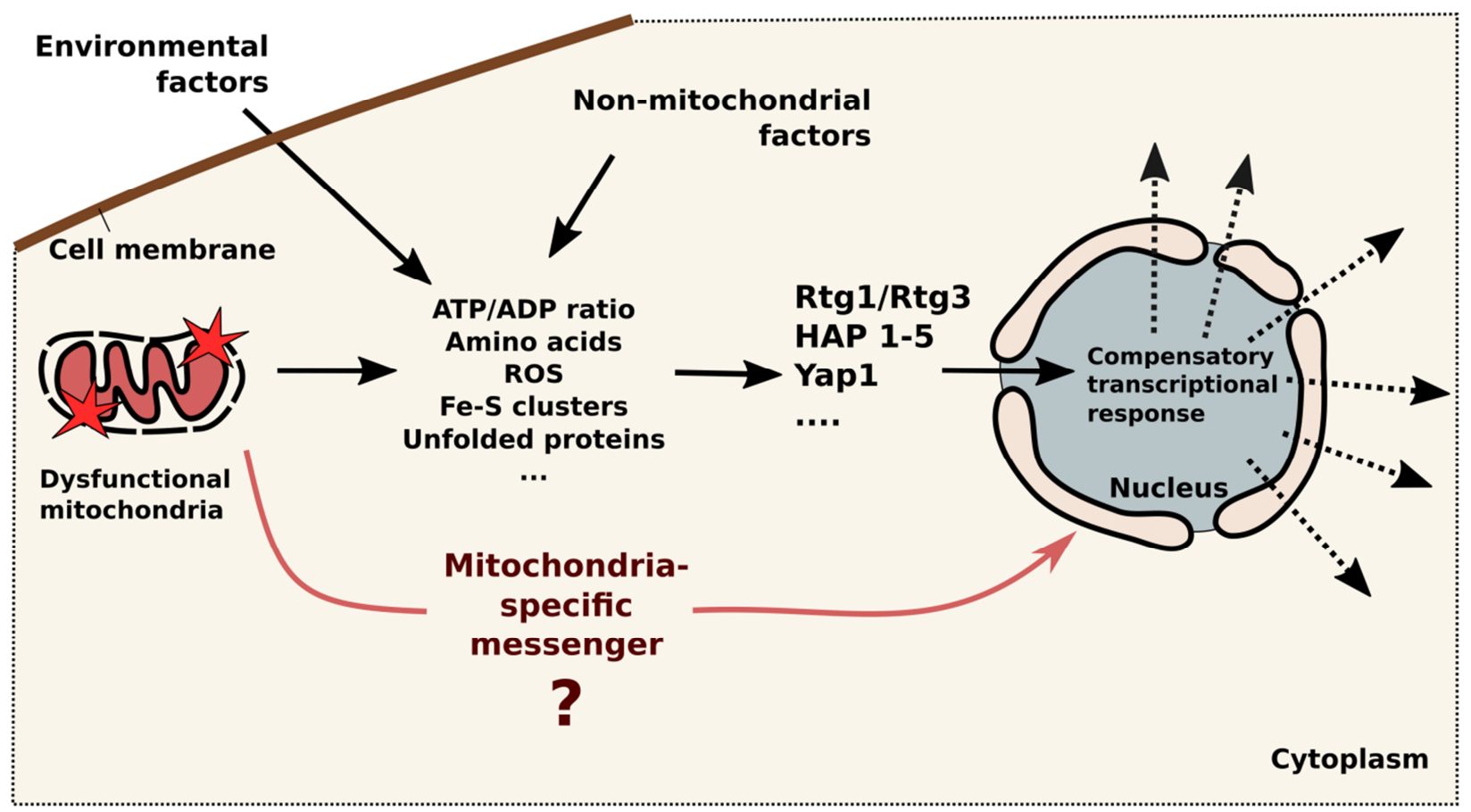

FIGURE 1: Schematic illustration of mitochondria-to-nucleus signaling in yeast. Mitochondrial dysfunction initiate change in concentrations of several factors in the cytoplasm (ATP, amino acids, ROS, Fe-S clusters, unfolded proteins and others), these concentrations also depend on environmental and non-mitochondrial factors. Then factors are detected by the cytosolic sensors (RTG1/RTG3, Hap 1-5, Yap1 and others) which transmit the signals to the nucleus leading to compensatory transcriptional response. Question mark indicates that the direct signaling routes are still not known. 
parental cells was much weaker [84]. An example of mitochondrial regulatory short peptide was recently discovered in mammalian cells. It was shown that MOTS-c transcript is exported from mitochondrial matrix and translated in cytoplasm, where it activates AMP-dependent kinase [85]. Although yeasts do not contain any regions with close homology to MOTS-c, their mitochondrial genome is relatively large and more complex than the human one (human mitochondria harbor shorter DNA, no introns, genes related to oxidative phosphorylation only), meaning that similar mechanisms could still be found in yeasts.

\section{RETROGRADE SIGNALING AND CELL CYCLE}

Mitochondria quantity and quality must be tracked during cell cycle progression, otherwise the daughter or mother cells could inherit insufficient or excessive amounts of the organelles. The former could lead to a complete depletion of mitochondria in some cells and consequent cell death. Indeed, in contrast to the loss of mitochondrial DNA, yeast cells cannot tolerate the loss of mitochondria. To our knowledge, there were no reports describing cases of mitochondria elimination from the wild type yeast cells, although malfunction of mitochondrial transport machinery can induce the formation of buds without mitochondria [86]. Thus, it seems likely that mitochondria transmit signal to the nuclei to control cell cycle progression depending on mtDNA and/or mitochondrial proteins abundance.

In 2004 Singh [87] suggested the existence of mitochondria-specific checkpoint, mitocheckpoint, which signals to the nucleus upon severe mtDNA damage. Later it was found that growth defects of yeast cells with compromised respiratory activity is due to Rad53-mediated delay of G1to S-phase transition [88]. Recent data also revealed that coordination of nuclear cell cycle progression with mitochondrial biogenesis is regulated at the level of protein import machinery [20]. We found that under nitrogen starvation conditions, mitochondria contribute to activation of pseudohyphal growth [31]. Such growth is associated with prolonged cell cycle delay in G2-phase [89]. We have also shown that signaling mediated by Rtg-proteins contributes to the severity of S-phase arrest induced by telomere dysfunction [90]. At the same time, early studies showed that cell cycle arrest does not prevent mtDNA overreplication $[18,19]$. Together, it suggests that although mitochondria influence cell cycle progression and activation of its specific modes (e.g. pseudohypha), mitochondrial signaling branch is integrated together with other signals which influence cell cycle progression.

\section{CONCLUSIONS}

To conclude, beyond their role in energy requirement, mitochondria are recognized as elements of signaling pathways convergence. A plethora of cellular processes rely on their proper functionality which is controlled by a tight cross talk between mitochondria and the nucleus (retrograde signaling) and vice versa (anterograde signaling). However, how cells sense mitochondrial functionality or mitochondria signal their status is still unclear and needs a better understanding. Yeast has been widely used as a model to study mitochondrial function for its metabolic features are highly conserved throughout the eukaryotic kingdom.

The presented data point that baker's yeast are devoid of specialized mitochondria-to-nucleus signaling pathways. Instead, mitochondria-initiated cascades are modulated by non-mitochondrial (cytosolic) factors (see Figure 1). Typically, mitochondrial compensatory response is initiated by the changes in concentrations of certain factors in the cytoplasm. Then such problem is detected by the specialized cytosolic sensors which modulate the transcription of the sets of genes (Figure 1). For example, a deficit of glutamate can be caused by malfunctioning mitochondria, by insufficient nitrogen source in the medium or by over-intense protein biosynthesis. The deficit is sensed by TOR complex, which activates Rtg cascade (to improve mitochondrial biosynthetic machinery), invasive growth (to seek nitrogen source) and also slows down the rate of protein synthesis. This does not necessarily mean that the cells are unable to produce transcriptional response which is aimed at mitochondria only. Possibly, a certain combination of changes in the cytosol, e.g. simultaneous drops in the concentrations of ATP and glutamate combined with mild oxidative stress, can induce transcriptional changes mainly affecting mitochondria. Also, it is still possible that the direct signaling routes, similar to mammalian MOTS-c - dependent pathway, do exist in yeast. In our opinion, it is likely that mPOS network is initiated by the specific precursors (as opposed to bulk misfolded protein). If so, such precursor can be considered as a classical signaling intermediate. Short peptides exported by mitochondrial ABC-transporter Mdl1 are also candidates for the role direct signaling molecules.

\section{ACKNOWLEDGEMENTS}

The study was supported by Russian Foundation for Basic Research grant 16-34-00197-a (the work of A. Zyrina, the section "Amino acids-based signaling"), and Russian Scientific Foundation grant 14-24-00107 (the rest of the work).

\section{CONFLICT OF INTEREST}

The authors declare no conflict of interest.

\section{COPYRIGHT}

(C) 2016 Knorre et al. This is an open-access article released under the terms of the Creative Commons Attribution (CC BY) license, which allows the unrestricted use, distribution, and reproduction in any medium, provided the original author and source are acknowledged.

Please cite this article as: Dmitry A. Knorre, Svyatoslav S. Sokolov, Anna N. Zyrina, Fedor F. Severin (2016). How do yeast sense mitochondrial dysfunction? Microbial Cell 3(11): 532-539. doi: 10.15698/mic2016.11.537 


\section{REFERENCES}

1. Zorov DB, Krasnikov BF, Kuzminova AE, Vysokikh MYu, and Zorova LD (1997). Mitochondria revisited. Alternative functions of mitochondria. Biosci Rep 17(6): 507-520.

2. Lill R and Kispal G (2000). Maturation of cellular Fe-S proteins: an essential function of mitochondria. Trends Biochem Sci 25(8): 352356

3. McBride HM, Neuspiel M, and Wasiak S (2006). Mitochondria: more than just a powerhouse. Curr Biol 16(14): R551-R560.

4. Zalman LS, Nikaido $H$, and Kagawa $Y$ (1980). Mitochondrial outer membrane contains a protein producing nonspecific diffusion channels. J Biol Chem 255(5): 1771-1774.

5. van Gurp M, Festjens N, van Loo G, Saelens X, and Vandenabeele P (2003). Mitochondrial intermembrane proteins in cell death. Biochem Biophys Res Commun 304(3): 487-497.

6. Du C, Fang M, Li Y, Li L, and Wang X (2000). Smac, a mitochondria protein that promotes cytochrome c-dependent caspase activation by eliminating IAP inhibition. Cell 102(1): 33-42.

7. Zou H, Henzel WJ, Liu X, Lutschg A, and Wang X (1997). Apaf-1, a human protein homologous to $C$. elegans CED-4, participates in cytochrome c-dependent activation of caspase-3. Cell 90(3): 405-413.

8. Ludovico $P$, Rodrigues $F$, Almeida A, Silva MT, Barrientos A, and Côrte-Real M (2002). Cytochrome $c$ release and mitochondria involvement in programmed cell death induced by acetic acid in Saccharomyces cerevisiae. Mol Biol Cell 13(8): 2598-2606.

9. Pozniakovsky AI, Knorre DA, Markova OV, Hyman AA, Skulachev VP, and Severin FF (2005). Role of mitochondria in the pheromone- and amiodarone-induced programmed death of yeast. J Cell Biol 168(2): 257-269.

10. Starkov AA (2008). The role of mitochondria in reactive oxygen species metabolism and signaling. Ann N Y Acad Sci 1147: 37-52.

11. Dröse $S$ and Brandt $U$ (2012). Molecular mechanisms of superoxide production by the mitochondrial respiratory chain. Adv Exp Med Biol 748: 145-169.

12. Klingenberg $M(\mathbf{1 9 8 0})$. The ADP-ATP translocation in mitochondria, a membrane potential controlled transport. J Membr Biol 56(2): 97105.

13. Bauer MF, Sirrenberg C, Neupert W, and Brunner M (1996). Role of Tim23 as Voltage Sensor and Presequence Receptor in Protein Import into Mitochondria. Cell 87(1): 33-41.

14. Hart PC, Mao M, de Abreu ALP, Ansenberger-Fricano K, Ekoue DN, Ganini D, Kajdacsy-Balla A, Diamond AM, Minshall RD, Consolaro MEL, Santos JH, and Bonini MG (2015). MnSOD upregulation sustains the Warburg effect via mitochondrial ROS and AMPK-dependent signalling in cancer. Nat Commun 6: 6053

15. Liu Z and Butow RA (2006). Mitochondrial retrograde signaling. Annu Rev Genet 40: 159-185.

16. Dirmeier R, O'Brien KM, Engle M, Dodd A, Spears E, and Poyton RO (2002). Exposure of yeast cells to anoxia induces transient oxidative stress. Implications for the induction of hypoxic genes. J Biol Chem 277(38): 34773-34784.

17. Meyer JN, Leung MCK, Rooney JP, Sendoel A, Hengartner MO, Kisby GE, and Bess AS (2013). Mitochondria as a target of environmental toxicants. Toxicol Sci 134(1): 1-17

18. Newlon CS and Fangman WL (1975). Mitochondrial DNA synthesis in cell cycle mutants of Saccharomyces cerevisiae. Cell 5(4): 423-428.
19. Sazer S and Sherwood SW (1990). Mitochondrial growth and DNA synthesis occur in the absence of nuclear DNA replication in fission yeast. J Cell Sci 97 ( Pt 3): 509-516.

20. Harbauer AB, Opalińska M, Gerbeth $C$, Herman JS, Rao S, Schönfisch B, Guiard B, Schmidt O, Pfanner N, and Meisinger C (2014). Mitochondria. Cell cycle-dependent regulation of mitochondrial preprotein translocase. Science 346(6213): 1109-1113.

21. Liao X and Butow RA (1993). RTG1 and RTG2: two yeast genes required for a novel path of communication from mitochondria to the nucleus. Cell 72(1): 61-71.

22. Rehácek Z, Ramankutty M, and Kozová J (1968). Respiratory chain of antimycin A-producing Streptomyces antibioticus. Appl Microbiol 16(1): 29-32.

23. Gerth K, Irschik H, Reichenbach H, and Trowitzsch W (1980). Myx othiazol, an antibiotic from Myxococcus fulvus (myxobacterales). I. Cultivation, isolation, physico-chemical and biological properties. J Antibiot 33(12): 1474-1479.

24. Hallstrom TC and Moye-Rowley WS (2000). Multiple signals from dysfunctional mitochondria activate the pleiotropic drug resistance pathway in Saccharomyces cerevisiae. J Biol Chem 275(48): 3734737356.

25. da Cunha FM, Torelli NQ, and Kowaltowski AJ (2015). Mitochondrial Retrograde Signaling: Triggers, Pathways, and Outcomes. Oxid Med Cell Longev 2015: 482582

26. Jazwinski SM (2015). Mitochondria to nucleus signaling and the role of ceramide in its integration into the suite of cell quality control processes during aging. Ageing Res Rev 23(Pt A): 67-74.

27. Miceli MV, Jiang JC, Tiwari A, Rodriguez-Quiñones JF, and Jazwinski SM (2011). Loss of mitochondrial membrane potential triggers the retrograde response extending yeast replicative lifespan. Front Genet 2: 102.

28. Zhang F, Pracheil T, Thornton J, and Liu Z (2013). Adenosine Triphosphate (ATP) Is a Candidate Signaling Molecule in the Mitochondria-to-Nucleus Retrograde Response Pathway. Genes 4(1): 86-100.

29. Warburg O (1956). On the origin of cancer cells. Science 123(3191): 309-314.

30. Guaragnella N, Zdralević M, Lattanzio P, Marzulli D, Pracheil T, Liu Z, Passarella S, Marra E, and Giannattasio S (2013). Yeast growth in raffinose results in resistance to acetic-acid induced programmed cell death mostly due to the activation of the mitochondrial retrograde pathway. Biochim Biophys Acta 1833(12): 2765-2774.

31. Starovoytova AN, Sorokin MI, Sokolov SS, Severin FF, and Knorre DA (2013). Mitochondrial signaling in Saccharomyces cerevisiae pseudohyphae formation induced by butanol. FEMS Yeast Res 13(4): 367374.

32. Traven A, Wong JM, Xu D, Sopta M, and Ingles CJ (2001). Interorganellar communication. Altered nuclear gene expression profiles in a yeast mitochondrial dna mutant. J Biol Chem 276(6): 4020-4027.

33. Epstein CB, Waddle JA, Hale W, Davé V, Thornton J, Macatee TL, Garner HR, and Butow RA (2001). Genome-wide responses to mitochondrial dysfunction. Mol Biol Cell 12(2): 297-308.

34. Twig G, Elorza A, Molina AJA, Mohamed H, Wikstrom JD, Walzer G, Stiles L, Haigh SE, Katz S, Las G, Alroy J, Wu M, Py BF, Yuan J, Deeney $\mathrm{JT}$, Corkey BE, and Shirihai OS (2008). Fission and selective fusion govern mitochondrial segregation and elimination by autophagy. EMBO J 27(2): 433-446. 
35. Twig G and Shirihai OS (2011). The interplay between mitochondrial dynamics and mitophagy. Antioxid Redox Signal 14(10): 19391951.

36. Nargund AM, Pellegrino MW, Fiorese CJ, Baker BM, and Haynes CM (2012). Mitochondrial import efficiency of ATFS-1 regulates mitochondrial UPR activation. Science 337(6094): 587-590.

37. Teixeira V, Medeiros TC, Vilaça R, Pereira AT, Chaves SR, CôrteReal $M$, Moradas-Ferreira $P$, and Costa V (2015). Ceramide signalling impinges on Sit $4 p$ and Hog $1 p$ to promote mitochondrial fission and mitophagy in Isc1p-deficient cells. Cell Signal 27(9): 1840-1849.

38. Gaspard GJ and McMaster CR (2015). The mitochondrial quality control protein Yme1 is necessary to prevent defective mitophagy in a yeast model of Barth syndrome. J Biol Chem 290(14): 9284-9298.

39. Nagi M, Tanabe K, Nakayama H, Ueno K, Yamagoe S, Umeyama T, Ohno H, and Miyazaki Y (2016). Iron-depletion promotes mitophagy to maintain mitochondrial integrity in pathogenic yeast Candida glabrata. Autophagy 12(8): 1259-1271.

40. Okamoto K, Kondo-Okamoto N, and Ohsumi Y (2009). Mitochondria-anchored receptor Atg32 mediates degradation of mitochondria via selective autophagy. Dev Cell 17(1): 87-97.

41. Eiyama A, Kondo-Okamoto N, and Okamoto K (2013). Mitochondrial degradation during starvation is selective and temporally distinct from bulk autophagy in yeast. FEBS Lett 587(12): 1787-1792.

42. McFaline-Figueroa JR, Vevea J, Swayne TC, Zhou C, Liu C, Leung G Boldogh IR, and Pon LA (2011). Mitochondrial quality control during inheritance is associated with lifespan and mother-daughter age asymmetry in budding yeast. Aging Cell 10(5): 885-895.

43. Higuchi R, Vevea JD, Swayne TC, Chojnowski R, Hill V, Boldogh IR, and Pon LA (2013). Actin dynamics affect mitochondrial quality control and aging in budding yeast. Curr Biol 23(23): 2417-2422

44. Knorre DA, Popadin KY, Sokolov SS, and Severin FF (2013). Roles of mitochondrial dynamics under stressful and normal conditions in yeast cells. Oxid Med Cell Longev 2013: 139491.

45. Wang X and Chen XJ (2015). A cytosolic network suppressing mitochondria-mediated proteostatic stress and cell death. Nature 524(7566): 481-484.

46. Morano KA, Grant CM, and Moye-Rowley WS (2012). The response to heat shock and oxidative stress in Saccharomyces cerevisiae. Genetics 190(4): 1157-1195.

47. Verghese J, Abrams J, Wang Y, and Morano KA (2012). Biology of the heat shock response and protein chaperones: budding yeast ( $S a c$ charomyces cerevisiae) as a model system. Microbiol Mol Biol Rev 76(2): 115-158.

48. Tenreiro S, Munder MC, Alberti S, and Outeiro TF (2013). Harnessing the power of yeast to unravel the molecular basis of neurodegeneration. J Neurochem 127(4): 438-452.

49. Fruhmann G, Seynnaeve D, Zheng J, Ven K, Molenberghs S, Wilms $\mathrm{T}$, Liu B, Winderickx J, and Franssens $V$ (2016). Yeast buddies helping to unravel the complexity of neurodegenerative disorders. Mech Ageing Dev.

50. Eisenberg-Bord $M$ and Schuldiner $M$ (2016). Ground control to major TOM: mitochondria-nucleus communication. FEBS J.

51. Morris SM (2004). Enzymes of arginine metabolism. J Nutr 134(10 Suppl): 2743S - 2747S; discussion 2765S - 2767S.

52. Kitagaki $\mathrm{H}$ and Takagi $\mathrm{H}$ (2014). Mitochondrial metabolism and stress response of yeast: Applications in fermentation technologies. J Biosci Bioeng 117(4): 383-393.
53. Crespo JL, Powers T, Fowler B, and Hall MN (2002). The TORcontrolled transcription activators GLN3, RTG1, and RTG3 are regulated in response to intracellular levels of glutamine. Proc Natl Acad Sci U S A 99(10): 6784-6789.

54. Dilova I, Aronova S, Chen JC-Y, and Powers T (2004). Tor signaling and nutrient-based signals converge on Mks1p phosphorylation to regulate expression of Rtg1.Rtg3p-dependent target genes. J Biol Chem 279(45): 46527-46535.

55. Giannattasio S, Liu Z, Thornton J, and Butow RA (2005). Retrograde response to mitochondrial dysfunction is separable from TOR $1 / 2$ regulation of retrograde gene expression. J Biol Chem 280(52): 42528-42535.

56. Dilova I, Chen C-Y, and Powers T (2002). Mks1 in concert with TOR signaling negatively regulates RTG target gene expression in $S$. cerevisiae. Curr Biol 12(5): 389-395.

57. Liu Z, Sekito T, Spírek M, Thornton J, and Butow RA (2003). Retrograde signaling is regulated by the dynamic interaction between $\operatorname{Rtg} 2 p$ and Mks1p. Mol Cell 12(2): 401-411.

58. Brand MD, Affourtit C, Esteves TC, Green K, Lambert AJ, Miwa S, Pakay JL, and Parker N (2004). Mitochondrial superoxide: production, biological effects, and activation of uncoupling proteins. Free Radic Biol Med 37(6): 755-767.

59. Balaban RS, Nemoto S, and Finkel T (2005). Mitochondria, oxidants, and aging. Cell 120(4): 483-495.

60. Bienert GP, Schjoerring JK, and Jahn TP (2006). Membrane transport of hydrogen peroxide. Biochim Biophys Acta 1758(8): 9941003.

61. Tahara EB, Barros MH, Oliveira GA, Netto LES, and Kowaltowski AJ (2007). Dihydrolipoyl dehydrogenase as a source of reactive oxygen species inhibited by caloric restriction and involved in Saccharomyces cerevisiae aging. FASEB J 21(1): 274-283.

62. Petrova VY, Drescher D, Kujumdzieva AV, and Schmitt MJ (2004). Dual targeting of yeast catalase $A$ to peroxisomes and mitochondria. Biochem J 380(Pt 2): 393-400.

63. Gomes F, Tahara EB, Busso C, Kowaltowski AJ, and Barros $\mathrm{MH}$ (2013). nde1 deletion improves mitochondrial DNA maintenance in Saccharomyces cerevisiae coenzyme Q mutants. Biochem J 449(3): 595-603.

64. Torelli NQ, Ferreira-Júnior JR, Kowaltowski AJ, and da Cunha FM (2015). RTG1- and RTG2-dependent retrograde signaling controls mitochondrial activity and stress resistance in Saccharomyces cerevisiae. Free Radic Biol Med 81: 30-37.

65. Bourges I, Horan S, and Meunier B (2005). Effect of inhibition of the bc1 complex on gene expression profile in yeast. J Biol Chem 280(33): 29743-29749.

66. Ma M and Liu ZL (2010). Mechanisms of ethanol tolerance in Saccharomyces cerevisiae. Appl Microbiol Biotechnol 87(3): 829-845.

67. Bleoanca I, Silva ARC, Pimentel C, Rodrigues-Pousada C, and Menezes R de A (2013). Relationship between ethanol and oxidative stress in laboratory and brewing yeast strains. J Biosci Bioeng 116(6): 697-705.

68. Delaunay A, Isnard AD, and Toledano MB (2000). H2O2 sensing through oxidation of the Yap1 transcription factor. EMBO J 19(19): 5157-5166.

69. Kaniak-Golik A and Skoneczna A (2015). Mitochondria-nucleus network for genome stability. Free Radic Biol Med 82: 73-104. 
70. Cohen BA, Pilpel Y, Mitra RD, and Church GM (2002). Discrimination between paralogs using microarray analysis: application to the Yap1p and Yap2p transcriptional networks. Mol Biol Cell 13(5): 16081614.

71. Venters BJ, Wachi S, Mavrich TN, Andersen BE, Jena $P$, Sinnamon AJ, Jain P, Rolleri NS, Jiang C, Hemeryck-Walsh C, and Pugh BF (2011). A comprehensive genomic binding map of gene and chromatin regulatory proteins in Saccharomyces. Mol Cell 41(4): 480-492.

72. Hon T, Dodd A, Dirmeier R, Gorman N, Sinclair PR, Zhang L, and Poyton RO (2003). A mechanism of oxygen sensing in yeast. Multiple oxygen-responsive steps in the heme biosynthetic pathway affect Hap1 activity. J Biol Chem 278(50): 50771-50780.

73. Lai L-C, Kosorukoff AL, Burke PV, and Kwast KE (2006). Metabolicstate-dependent remodeling of the transcriptome in response to anoxia and subsequent reoxygenation in Saccharomyces cerevisiae. Eukaryot Cell 5(9): 1468-1489.

74. Creusot F, Verdière J, Gaisne $M$, and Slonimski PP (1988). CYP1 (HAP1) regulator of oxygen-dependent gene expression in yeast. I. Overall organization of the protein sequence displays several novel structural domains. J Mol Biol 204(2): 263-276.

75. Pfeifer K, Kim KS, Kogan S, and Guarente L (1989). Functional dissection and sequence of yeast HAP1 activator. Cell 56(2): 291-301.

76. Zhang $L$ and Hach $A$ (1999). Molecular mechanism of heme signaling in yeast: the transcriptional activator Hap1 serves as the key mediator. Cell Mol Life Sci 56(5-6): 415-426.

77. Keng T, Richard C, and Larocque R (1992). Structure and regulation of yeast HEM3, the gene for porphobilinogen deaminase. Mol Gen Genet 234(2): 233-243.

78. Buschlen S, Amillet J-M, Guiard B, Fournier A, Marcireau C, and Bolotin-Fukuhara M (2003). The S. Cerevisiae HAP complex, a key regulator of mitochondrial function, coordinates nuclear and mitochondrial gene expression. Comp Funct Genomics 4(1): 37-46.

79. Yoboue ED, Mougeolle A, Kaiser L, Averet N, Rigoulet M, and Devin $A$ (2014). The role of mitochondrial biogenesis and ROS in the control of energy supply in proliferating cells. Biochim Biophys Acta 1837(7): 1093-1098.

80. Kispal G, Csere P, Prohl C, and Lill R (1999). The mitochondrial proteins Atm1p and Nfs1p are essential for biogenesis of cytosolic Fe/S proteins. EMBO J 18(14): 3981-3989.
81. Gompf S, Zutz A, Hofacker M, Haase W, van der Does C, and Tampé R (2007). Switching of the homooligomeric ATP-binding cassette transport complex MDL1 from post-translational mitochondrial import to endoplasmic reticulum insertion. FEBS J 274(20): 5298-5310.

82. Prasad R and Goffeau A (2012). Yeast ATP-binding cassette transporters conferring multidrug resistance. Annu Rev Microbiol 66: 3963.

83. Young L, Leonhard K, Tatsuta T, Trowsdale J, and Langer T (2001). Role of the $A B C$ transporter Mdl1 in peptide export from mitochondria. Science 291(5511): 2135-2138.

84. Arnold I, Wagner-Ecker M, Ansorge W, and Langer T (2006). Evidence for a novel mitochondria-to-nucleus signalling pathway in respiring cells lacking i-AAA protease and the ABC-transporter Mdl1. Gene 367: 74-88.

85. Lee C, Zeng J, Drew BG, Sallam T, Martin-Montalvo A, Wan J, Kim S-J, Mehta H, Hevener AL, de Cabo R, and Cohen P (2015). The Mitochondrial-Derived Peptide MOTS-c Promotes Metabolic Homeostasis and Reduces Obesity and Insulin Resistance. Cell Metab 21(3): 443454.

86. Altmann K, Frank M, Neumann D, Jakobs S, and Westermann B (2008). The class $V$ myosin motor protein, Myo2, plays a major role in mitochondrial motility in Saccharomyces cerevisiae. J Cell Biol 181(1): 119-130.

87. Singh KK (2004). Mitochondria damage checkpoint in apoptosis and genome stability. FEMS Yeast Res 5(2): 127-132.

88. Crider DG, García-Rodríguez LJ, Srivastava P, Peraza-Reyes L, Upadhyaya K, Boldogh IR, and Pon LA (2012). Rad53 is essential for a mitochondrial DNA inheritance checkpoint regulating $\mathrm{G} 1$ to $S$ progression. J Cell Biol 198(5): 793-798.

89. Kron SJ, Styles CA, and Fink GR (1994). Symmetric cell division in pseudohyphae of the yeast Saccharomyces cerevisiae. Mol Biol Cell 5(9): 1003-1022.

90. Zyrina AN, Sorokin MI, Sokolov SS, Knorre DA, and Severin FF (2015). Mitochondrial retrograde signaling inhibits the survival during prolong S/G2 arrest in Saccharomyces cerevisiae. Oncotarget 6(42): 44084-44094. 